\title{
Acyclovir inhibition of IDO to decrease Tregs as a glioblastoma treatment adjunct
}

\author{
Johan Söderlund ${ }^{1}$, Sophie Erhardt ${ }^{1}$, Richard E Kast ${ }^{2^{*}}$
}

\begin{abstract}
Regulatory T cells, Tregs, are a subset of lymphocytes that have immunosuppressive attributes. They are elevated in blood of glioblastoma patients and within this tumor's tissue itself. Indoleamine 2,3-dioxygenase, IDO, converts tryptophan to kynurenine. IDO activity enhances Treg formation by pathways that are unknown. Experimentally, inhibition of IDO decreases Treg function and number in rodents. The common anti-viral agent acyclovir inhibits IDO. Acyclovir may thereby decrease Treg function in glioblastoma. If it can be confirmed that Treg counts are elevated in glioblastoma patients' tumor tissue, and if we can document acyclovir's lowering of tissue Treg counts by a small trial of acyclovir in pre-operative glioblastoma patients, a trial of acyclovir effect on survival should be done given the current poor prognosis of glioblastoma and the well-established safety and low side effect burden of acyclovir.
\end{abstract}

\section{Background}

Glioblastoma constitutes about half of all primary brain tumors and has a median survival time of 10 to 18 months with current standard treatment of maximal primary resection, irradiation, and temozolomide [1,2]. In the effort to find better treatments we reviewed past research on immunosuppressive lymphocytes in glioblastoma and looked for data that might indicate a clinically realizable path using currently available drugs to inhibit immunosuppressive lymphocytes.

An established antiviral drug, acyclovir, is known to inhibit indoleamine 2,3-dioxygenase (IDO) [3-5], an enzyme that is important in development of immunosuppressive lymphocytes. This paper outlines the experimental data generating this story and suggests that acyclovir might be a potential treatment adjunct for glioblastoma if past research can be confirmed.

\section{Tregs and the kynurenine pathway}

Multiple lines of evidence point to a mild but clear state of systemic immunosuppression in patient with glioblastoma [6-9]. Why or how this comes about is not clear [6]. One probable contributor to this immunosuppressed

\footnotetext{
* Correspondence: rekast@email.com

${ }^{2}$ Department of Psychiatry, University of Vermont, 22 Church Street, Burlington, VT 05401, USA

Full list of author information is available at the end of the article
}

state is IDO-mediated biasing of immune responses as outlined below.

Professional antigen presenting cells, such as dendritic cells (DCs), in addition to activating effects on cytotoxic $\mathrm{T}$ cells, may also recruit Foxp3-expressing CD4+CD25+ regulatory $\mathrm{T}$ cells (Tregs) to suppress cytotoxic responses. Trials of DC-based immunotherapy for glioblastoma $[9,10]$ are currently being pursued, but these are hampered by the fact that DCs may have either an immunostimulatory or immunosuppressive phenotype $[9,10]$. As in the case for Tregs, the immunosuppressive DC phenotype is associated with IDO, as discussed below.

In vitro-generated Tregs express interleukin-2 (IL-2) receptors (CD25) but, unlike cytotoxic $\mathrm{T}$ cells, they do not proliferate or produce IL-2 upon ligation of $\mathrm{T}$ cell receptors (TCRs). In contrast, they inhibit IL-2 production by and TCR-induced proliferation of co-cultured T cells [11-13]. However, in vivo, Tregs themselves may well proliferate vigorously in response to TCR ligation while retaining their proliferation-inducing activity on effector lymphocytes [11-13]. This suggests that, in vivo, Tregs are active and specific participants in the suppression of antigen-driven immune responses.

Outside the thymus, de novo recruitment of Tregs is associated with tryptophan metabolism along the kynurenine pathway. The first step in the kynurenine pathway is conversion of tryptophan to formylkynurenine via the 
rate-limiting enzyme IDO or, in liver, via the related enzyme tryptophan 2, 3 dioxygenase (TDO) $[14,15]$.

Activation of IDO in DCs during Treg recruitment is a well-replicated finding [16-21]. Diminished availability of tryptophan down-regulates the mammalian target of rapamycin, mTOR [22]. Diminished mTOR expression in DCs increases the recruitment and generation of FoxP3 expressing Treg [23,24]. Moreover, inhibition of IDO by 1-MT, an experimental IDO inhibitor, has been shown to inhibit Treg recruitment by plasmacytoid DCs while the addition of exogenous kynurenine enhances Treg recruitment by plasmacytoid DCs [25].

The determinants of generation of DC function to immunity or tolerance are unclear, but their environmental flexibility may be substantial [9]. Thus, the ligation of co-stimulatory molecule B7-1 on DCs by soluble or $\mathrm{T}$ cell membrane-bound cytotoxic $\mathrm{T}$ lymphocyte antigen-4 (CTLA-4) converts DCs to a tolerogenic phenotype [26] accompanied by evidence of increased IDO-dependent tryptophan catabolism [26]. This tolerogenic phenotype is obviated by enhanced proteosomal IDO degradation [26]. Immunogenic DCs lack IDO synthetic ability but acquire a tolerogenic phenotype if exposed to IDO-competent DCs and their paracrine functioning kynurenines [27].

CD8-DCs do not produce transforming growth factorbeta (TGF- $\beta$ ). Exogenous TGF- $\beta$ will induce IDO in such cells and turns them from immunogenic into tolerogenic cells [28].

\section{Acyclovir}

Introduced in the early 1980's, acyclovir was the fifth antiviral drug to see common use. It is thought to inhibit a specific thymidine kinase of certain Herpes viruses, most notably Herpes simplex [29]. Acyclovir is renally excreted with a circulating T1/2 of 3 hours. It is a welltolerated, inexpensive drug with few side effects that is marketed worldwide [29].

Acyclovir has been shown to inhibit both IDO and TDO in homogenates of rat intestine [4] and liver [3]. Rat liver TDO is inhibited by acyclovir administered in vitro as well as in vivo [3]. The superoxide anion scavenging properties of acyclovir have been suggested as the mechanism underlying these actions $[4,5]$, since superoxide anion is needed to activate the IDO/TDO enzyme.

Acyclovir is commonly used against Herpes labialis outbreaks, a condition often associated with or provoked by life stressors, presumably secondary to stress-related temporary loss of immune control. As discussed above, activation of the TDO/IDO complex is associated with recruitment of Tregs and thus suppression of specific immune responses. Since TDO is stimulated by cortisol and other adrenal corticosteroids [30] we suggest that one mechanism underlying stress-related Herpes labialis outbreaks is increased activity of TDO, which upregulates Treg activity. Stressors readily and dramatically increase adrenal synthesis of cortisol in all mammals that have been tested.

\section{Tregs in glioblastoma}

$\mathrm{T}$-cell proliferative defects are readily demonstrated in glioblastoma patients, and Treg overrepresentation is contributory to that state [31].

A core finding pointing to the potential utility of acyclovir use in glioblastoma is that glioblastoma cells are readily stimulated by interferon- $\gamma \mathrm{s}$ and other stimuli, to upregulate IDO [32-36]. Although Tregs could be formed independently of IDO activation, the upregulation of IDO found within glioblastoma tissue is likely responsible, in part, for the enhanced presence of Tregs [37-41] within this tumor's tissue.

The concept and phenomenon of Treg-assisted evasion of specific immune responses against tumor antigens has been explored in other cancers. As examples: a) metastatic malignant melanoma expression of IDO is associated with increased numbers of Tregs, and higher numbers of such cells correlate with shorter survival [42], or b) the presence of Foxp3+ Tregs in breast cancer is associated with more advanced and aggressive disease [43].

The high number of FoxP3+ Treg cells in glioblastoma tissue [37-41], as compared to its complete absence in normal brain tissue, suggests that glioblastoma growth may benefit from the immunosuppressive activity of Tregs, and that glioblastoma patients will benefit from inhibiting Treg development with acyclovir. Although the degree of Treg infiltration does not have prognostic significance [38], experimental systemic Treg depletion has been shown to prolong survival in a murine orthotopic glioblastoma model, if depletion is done early after tumor implantation [39].

In addition to Tregs, myeloid cells with immature antigen-presenting phenotype are found within glioblastoma tissue $[7,9]$. Such cells can recruit circulating Tregs. In support of such a notion, monocytes cocultured in vitro with glioblastoma cells acquire a phenotype characterized by high surface expression of TGF- $\beta$ [7]. Increased production of TGF- $\beta$, elevated surface expression of TGF- $\beta$ receptors, and activation of its signaling pathways has been shown to be important elements of glioblastoma growth promotion [8].

Freshly resected glioblastoma tissue synthesizes and secretes CCL2, a chemokine also associated with the recruitment of Treg. CCL2 is the only chemokine detected in glioblastoma tissue by enzyme-linked immunosorbent assay, indicating that CCL2 may be the principal chemokine for Treg migration to glioblastoma 
tissue [44]. CCL2 is a $13 \mathrm{kDa}$ chemokine, also known as monocyte chemoattractant protein-1 [45].

A wealth of data implicates CCL5 as a paracrine/autocrine growth factor in glioblastoma [46]. The receptor for CCL5, CCR5, heterodimerizes with CCR2, the cognate receptor for CCL2. When the half of that dimer corresponding to CCR5 is blocked, CCL2 cannot signal even though binding to CCR2 is unimpaired. The recently approved and marketed anti-HIV drug maraviroc blocks CCL5 signaling at CCR5 [46]. Maraviroc has been proposed as treatment adjunct for glioblastoma based on documentation of CCR5 presence in glioblastomas and CCR5 function in glioblastoma growth stimulation [46]. Maraviroc therefore would have potential for inhibiting Treg migration to glioblastoma tissue as well as inhibition of CCR5 growth stimulation itself. Miraviroc may lower glioblastoma tissue Tregs in addition to acyclovir.

A second compelling reason to investigate acyclovir comes from the collective data of Cobbs et al. [47], Scheurer et al. [48], Mitchell et al. [49], and Prins et al. [50]. These researchers report detection of cytomegalovirus (CMV) in peripheral blood leukocytes and tumor tissue of glioblastoma patients but not in other conditions affecting the brain [47-50], indicating a potential role of CMV in glioblastoma pathogenesis.

Thus, acyclovir may prolong survival of glioblastoma patients also via its inhibition of thymidine kinase, which is expressed by CMV-infected cells. Another antiviral agent, gancyclovir, is marginally more efficient than acyclovir against CMV and may therefore also be interesting to test as adjunct to current glioblastoma protocol, although its inhibitory activity against IDO remains unknown.

Since reactivation of CMV either due to glioblastomaassociated immunosupression or secondary to temozolomide treatment is occasionally seen [51], acycloivir may be of service here too.

In accordance with our hypothesis of induction of IDO and recruitment of Tregs, a case study of a glioblastoma patient has described the development of a strong CMV-specific $\mathrm{T}$ cell response elicited by treatment with autologous tumor lysate-pulsed DCs [50].

\section{Conclusion}

Given the short survival with current treatments following a diagnosis of glioblastoma and the low risks of acyclovir, a human trial of acyclovir as adjunctive treatment is warranted if preliminary trials in normal individuals show evidence of acyclovir suppression of circulating Tregs.

The hypothesis presented in this paper could be easily tested by quantitative immunocytophoresis of circulating Tregs in peripheral blood of normal volunteers before and after several days of acyclovir $200 \mathrm{mg}$ p.o. four times daily. The safety of this dose is clear in that such treatment is commonly given without laboratory monitoring to patients to shorten an outbreak of Herpes simplex. Alternatively a naturalistic study of circulating Tregs by immunocytophoresis in people entering such Herpes outbreak treatment could give a good indication whether to proceed to a trial in glioblastoma or not.

\section{Author details}

'Department of Physiology \& Pharmacology, Karolinska Institutet, SE 17177 Stockholm, Sweden. ${ }^{2}$ Department of Psychiatry, University of Vermont, 22 Church Street, Burlington, VT 05401, USA.

\section{Authors' contributions}

All authors contributed equally to all aspects of this work and have read and approved the final manuscript.

\section{Competing interests}

The authors declare that they have no competing interests.

Received: 1 June 2010 Accepted: 6 August 2010

Published: 6 August 2010

\section{References}

1. Helseth R, Helseth E, Johannesen TB, Langberg CW, Lote K, Rønning P, Scheie D, Vik A, Meling TR: Overall survival, prognostic factors, and repeated surgery in a consecutive series of 516 patients with glioblastoma multiforme. Acta Neurol Scand 2010.

2. Seiz M, Krafft U, Freyschlag CF, Weiss C, Schmieder K, Lohr F, Wenz F, Thomé C, Tuettenberg J: Long-term adjuvant administration of temozolomide in patients with glioblastoma multiforme: experience of a single institution. J Cancer Res Clin Oncol 2010.

3. Müller AC, Daya S: Acyclovir inhibits rat liver tryptophan-2,3-dioxygenase and induces a concomitant rise in brain serotonin and 5-hydroxyindole acetic acid levels. Metab Brain Dis 2008, 23:351-60.

4. Müller AC, Dairam A, Limson JL, Daya S: Mechanisms by which acyclovir reduces the oxidative neurotoxicity and biosynthesis of quinolinic acid. Life Sci 2007, 80:918-25.

5. Müller AC, Maharaj H, Maharaj DS, Daya S: Aciclovir protects against quinolinic-acid-induced oxidative neurotoxicity. J Pharm Pharmacol 2005, 57:883-8.

6. Waziri A: Glioblastoma-derived mechanisms of systemic immunosuppression. Neurosurg Clin N Am 2010, 21:31-42.

7. Rodrigues JC, Gonzalez GC, Zhang L, Ibrahim G, Kelly JJ, Gustafson MP, Lin Y, Dietz AB, Forsyth PA, Yong WW, Parney IF: Normal human monocytes exposed to glioma cells acquire myeloid-derived suppressor cell-like properties. Neuro Oncol 2010, 12:351-65.

8. Kjellman C, Olofsson SP, Hansson O, Von Schantz T, Lindvall M, Nilsson I, Salford LG, Sjögren HO, Widegren B: Expression of TGF-beta isoforms, TGF-beta receptors, and SMAD molecules at different stages of human glioma. Int J Cancer 2000, 89:251-8.

9. Pellegatta S, Poliani PL, Stucchi E, Corno D, Colombo CA, Orzan F, Ravanini M, Finocchiaro G: Intra-tumoral dendritic cells increase efficacy of peripheral vaccination by modulation of glioma microenvironment. Neuro Oncol 2010, 12:377-8.

10. Luptrawan A, Liu G, Yu JS: Dendritic cell immunotherapy for malignant gliomas. Rev Recent Clin Trials 2008, 3:10-21.

11. Klein $L$, Khazaie $K$, von Boehmer $H$ : In vivo dynamics of antigen-specific regulatory $\mathrm{T}$ cells not predicted from behavior in vitro. Proc Natl Acad Sci USA 2003, 100:8886-91.

12. Walker LS: CD4+ CD25+ Treg: divide and rule? Immunology 2004, 111:129-37.

13. Walker LS, Chodos A, Eggena M, Dooms H, Abbas AK: Antigen-dependent proliferation of CD4+ CD25+ regulatory T cells in vivo. J Exp Med 2003, 198:249-58. 
14. Fallarino F, Grohmann U, You S, McGrath BC, Cavener DR, Vacca C, Orabona C, Bianchi R, Belladonna ML, Volpi C, Santamaria P, Fioretti MC, Puccetti P: The combined effects of tryptophan starvation and tryptophan catabolites down-regulate $T$ cell receptor zeta-chain and induce a regulatory phenotype in naive T cells. J Immunol 2006, 176:6752-61.

15. Grohmann U, Fallarino F, Puccetti P: Tolerance, DCs and tryptophan: much ado about IDO. Trends Immunol 2003, 24:242-8.

16. Chung DJ, Rossi M, Romano E, Ghith J, Yuan J, Munn DH, Young JW: IDOexpressing mature human monocyte-derived dendritic cells expand potent autologous regulatory T cells. Blood 2009, 114:555-63.

17. Kong QF, Sun B, Wang GY, Zhai DX, Mu LL, Wang DD, Wang JH, Li R, Li HL: BM stromal cells ameliorate experimental autoimmune myasthenia gravis by altering the balance of Th cells through the secretion of IDO. Eur J Immunol 2009, 39:800-9.

18. Chen W, Liang X, Peterson AJ, Munn DH, Blazar BR: The IDO pathway is essential for human plasmacytoid dendritic cell-induced adaptive $T$ regulatory cell generation. J Immunol 2008, 181:5396-404

19. Mahnke K, Bedke T, Enk AH: Regulatory conversation between antigen presenting cells and regulatory $T$ cells enhance immune suppression. Cell Immunol 2007, 250:1-13.

20. Sharma MD, Baban B, Chandler P, Hou DY, Singh N, Yagita H, Azuma M, Blazar BR, Mellor AL, Munn DH: Plasmacytoid dendritic cells from mouse tumor-draining lymph nodes directly activate mature Tregs via IDO. J Clin Invest 2007, 117:2570-82.

21. Munn DH, Mellor AL: IDO and tumor-induced tolerance. J Clin Invest 2007, 117:1147-54.

22. Hara K, Yonezawa K, Weng QP, Kozlowski MT, Belham C, Avruch J: Amino acid sufficiency and mTOR regulate p70 S6 kinase and elF-4E BP1 through a common effector mechanism. J Biol Chem 1998, 273:14484-94.

23. Turner MS, Kane LP, Morel PA: Dominant role of antigen dose in CD4 +Foxp3+ regulatory T cell induction and expansion. J Immunol 2009, 183:4895-903.

24. Kohlhaas S, Garden OA, Scudamore C, Turner M, Okkenhaug K, Vigorito E: Cutting edge: the Foxp3 target miR-155 contributes to the development of regulatory T cells. J Immunol 2009, 182:2578-82.

25. Chen W, Liang X, Peterson AJ, Munn DH, Blazar BR: The IDO pathway is essential for human plasmacytoid dendritic cell-induced adaptive $T$ regulatory cell generation. J Immunol 2008, 181:5396-404

26. Orabona C, Pallotta MT, Volpi C, Fallarino F, Vacca C, Bianchi $R$, Belladonna ML, Fioretti MC, Grohmann U, Puccetti P: SOCS3 drives proteasomal degradation of IDO and antagonizes IDO-dependent tolerogenesis. Proc Natl Acad Sci USA 2008, 105:20828-33.

27. Belladonna ML, Puccetti P, Orabona C, Fallarino F, Vacca C, Volpi C, Gizzi S, Pallotta MT, Fioretti MC, Grohmann U: Immunosuppression via tryptophan catabolism: the role of kynurenine pathway enzymes. Transplantation 2007, 84:517-20.

28. Belladonna ML, Volpi C, Bianchi R, Vacca C, Orabona C, Pallotta MT, Boon L, Gizzi S, Fioretti MC, Grohmann U, Puccetti P: Cutting edge: Autocrine TGFbeta sustains default tolerogenesis by IDO-competent dendritic cells. J Immunol 2008, 181:5194-8.

29. Lietman PS: Acyclovir clinical pharmacology An overview. Am J Med 1982, 73:193-6.

30. Liao M, Pabarcus MK, Wang Y, Hefner C, Maltby DA, Medzihradszky KF, Salas-Castillo SP, Yan J, Maher JJ, Correia MA: Impaired dexamethasonemediated induction of TDO in heme-deficient rat hepatocytes: translational control by a hepatic elF2alpha kinase, the heme-regulated inhibitor. J Pharmacol Exp Ther 2007, 323:979-89.

31. Carpentier AF, Meng Y: Recent advances in immunotherapy for human glioma. Curr Opin Oncol 2006, 18:631-6.

32. Däubener W, Mackenzie CR: IFN-gamma activated IDO activity in human cells is an antiparasitic and an antibacterial effector mechanism. Adv Exp Med Biol 1999, 467:517-24.

33. MacKenzie CR, González RG, Kniep E, Roch S, Däubener W: Cytokine mediated regulation of interferon-gamma-induced IDO activation. Adv Exp Med Biol 1999, 467:533-9.

34. MacKenzie CR, Willberg CB, Däubener W: Inhibition of group B streptococcal growth by IFN gamma-activated human glioblastoma cells. J Neuroimmunol 1998, 89:191-7.

35. Daubener W, Remscheid C, Nockemann S, Pilz K, Seghrouchni S, Mackenzie C, Hadding U: Anti-parasitic effector mechanisms in human brain tumor cells: role of interferon-gamma and tumor necrosis factoralpha. Eur J Immunol 1996, 26:487-92.

36. Daubener W, Pilz K, Seghrouchni Zennati S, Bilzer T, Fischer HG, Hadding U: Induction of toxoplasmostasis in a human glioblastoma by interferon gamma. J Neuroimmunol 1993, 43:31-8.

37. Banissi C, Ghiringhelli F, Chen L, Carpentier AF: Treg depletion with a lowdose metronomic temozolomide regimen in a rat glioma model. Cancer Immunol Immunother 2009, 58:1627-34.

38. Heimberger AB, Abou-Ghazal M, Reina-Ortiz C, Yang DS, Sun W, Qiao W, Hiraoka N, Fuller GN: Incidence and prognostic impact of FoxP3+ regulatory T cells in human gliomas. Clin Cancer Res 2008, 14:5166-72.

39. Curtin JF, Candolfi M, Fakhouri TM, Liu C, Alden A, Edwards M, Lowenstein PR, Castro MG: Treg depletion inhibits efficacy of cancer immunotherapy: implications for clinical trials. PLoS One 2008, 3:e1983.

40. El Andaloussi A, Lesniak MS: CD4+ CD25+ FoxP3+ T-cell infiltration and heme oxygenase-1 expression correlate with tumor grade in human gliomas. J Neurooncol 2007, 83:145-52.

41. Jordan JT, Sun W, Hussain SF, DeAngulo G, Prabhu SS: Preferential migration of regulatory $T$ cells mediated by glioma-secretedchemokines can be blocked with chemotherapy. Cancer Immunol Immunother 2008, 57:123-31

42. Brody JR, Costantino CL, Berger AC, Sato T, Lisanti MP, Yeo CJ, Emmons RV, Witkiewicz AK: Expression of IDO in metastatic malignant melanoma recruits regulatory $T$ cells to avoid immune detection and affects survival. Cell Cycle 2009, 8:1930-4

43. Mansfield AS, Heikkila PS, Vaara AT, von Smitten KA, Vakkila JM, Leidenius MH: Simultaneous Foxp3 and IDO expression is associated with sentinel lymph node metastases in breast cancer. BMC Cancer 2009, 9:231.

44. Jordan JT, Sun W, Hussain SF, DeAngulo G, Prabhu SS, Heimberger AB: Preferential migration of regulatory $T$ cells mediated by glioma-secreted chemokines blocked with chemotherapy. Cancer Immunol Immunother 2008, 57:123-31.

45. Deshmane SL, Kremlev S, Amini S, Sawaya BE: Monocyte chemoattractant protein-1 (MCP-1): an overview. J Interferon Cytokine Res 2009, 29:313-26.

46. Kast RE: Glioblastoma: synergy of growth promotion between CCL5 and NK-1R can be thwarted by blocking CCL5 with miraviroc, an FDA approved anti-HIV drug and blocking NK-1R with aprepitant, an FDA approved anti-nausea drug. J Clin Pharm \& Therapeutics 2010.

47. Cobbs CS, Harkins L, Samanta M, Gillespie GY, Bharara S, King PH, Nabors LB, Cobbs CG, Britt WJ: Human cytomegalovirus infection and expression in human malignant glioma. Cancer Res 2002, 62:3347-50.

48. Scheurer ME, Bondy ML, Aldape KD, Albrecht T, El-Zein R: Detection of human cytomegalovirus in different histological types of gliomas. Acta Neuropathol 2008, 116:79-86.

49. Mitchell DA, Xie W, Schmittling R, Learn C, Friedman A, McLendon RE, Sampson $\mathrm{JH}$ : Sensitive detection of human cytomegalovirus in tumors and peripheral blood of patients diagnosed with glioblastoma. Neuro Oncol 2008, 10:10-8

50. Prins RM, Cloughesy TF, Liau LM: Cytomegalovirus immunity after vaccination with autologous glioblastoma lysate. N Engl J Med 2008 359:539-41.

51. Meije Y, Lizasoain M, García-Reyne A, Martínez P, Rodríguez V, LópezMedrano $F$, Juan RS, Lalueza A, Aguado JM: Emergence of cytomegalovirus disease in patients receiving temozolomide: report of two cases and literature review. Clin Infect Dis 2010, 50:e73-6.

doi:10.1186/1742-2094-7-44

Cite this article as: Söderlund et al: Acyclovir inhibition of IDO to decrease Tregs as a glioblastoma treatment adjunct. Journal of Neuroinflammation 2010 7:44. 